\title{
Optical coherence tomography guided peeling of macular epiretinal membrane
}

This article was published in the following Dove Press journal:

Clinical Ophthalmology

23 December 2010

Number of times this article has been viewed

\section{Yoshio Hirano \\ Tsutomu Yasukawa \\ Yuichiro Ogura}

Department of Ophthalmology and Visual Science, Nagoya City

University Graduate School of

Medical Sciences, Nagoya, Japan
Correspondence: Yoshio Hirano Department of Ophthalmology and Visual Science, Nagoya City University Graduate School of Medical Sciences, I-Kawasumi, Mizuho-cho, Mizuho-ku, Nagoya 467-860I, Japan Tel +8 I 52853825 I

Fax +8I 528419490

Email yossyeye@med.nagoya-cu.ac.jp
Abstract: Optical coherence tomography (OCT) has emerged as a powerful diagnostic aid in disorders of the vitreoretinal juncture. The purpose of this study is to determine whether OCT can be used as an additional tool for evaluating an architecture including the thickened area, and the identifiable edge of a macular epiretinal membrane (ERM), and helping us to dissect the ERM from the retinal surface more easily and safely. In two cases with ERM, the edges of the membranes were detected by OCT, and the peeling of the membrane was started at the area easily. OCT guided ERM peeling might be useful for dissecting ERM membranes without any hesitation.

Keywords: optical coherence tomography, epiretinal membrane, vitrectomy

A macular epiretinal membrane usually develops after a partial or complete posterior vitreous detachment, and appears as a translucent membrane over the inner retinal surface in the macular area by ophthalmoscopy or biomicroscopy. Contraction of these membranes can result in various retinal pathologies, such as retinal distortion, increased thickness of the macula with or without increased permeability of retinal vessels, and cystoids macular edema.

Vision is decreased in eyes with macular epiretinal membranes for a variety of reasons: one or more full-thickness retinal folds, a trampoline-like sensory foveal elevation (tabletop-like traction), foveal ectopia created by an eccentric epiretinal membrane, retinal vascular leakage and macular edema, the presence of an opaque, dense membrane directly over the fovea, and traction-induced stasis of axoplasmic flow. ${ }^{1}$

The goal of surgery is to relieve the traction caused by the macular epiretinal membrane. Frequently, the membrane can be directly visualized. If the membrane is difficult to identify, indocyanine green (ICG), ${ }^{2}$ trypan blue, ${ }^{3}$ and intravitreal triamcinolone crystals ${ }^{4}$ have been described to aid the surgeon in identifying the internal limiting membrane. If the membrane is thick and fibrotic, it may be possible to grasp the membrane directly with an intraocular end-grasping forceps and strip it away from the macular surface. In most cases, however, a barbed microvitreoretinal (MVR) blade or 25-gauge needle is employed to engage the membrane at its edge and elevate it from the retinal surface. The blade is then used to strip away connections to the retina on that side of the membrane where the dissection was initiated. During this initial maneuver, a "front" of elevated membranes is created, taking care not to fragment the membrane by pulling too hard or too long in any one direction. Once an entire side of the membrane has been elevated, fine-tipped intraocular forceps are used to continue 
the dissection. This dissection should be started over the thickest part of the membrane, or the identifiable edge of the membrane.

Optical coherence tomography (OCT) has emerged as a powerful diagnostic aid in disorders of the vitreoretinal juncture. ${ }^{5}$ The use of OCT has allowed clinicians to evaluate the architecture and cross-sectional thickness of the neurosensory retina and its anatomic relationship to the retinal pigment epithelium and posterior hyaloids. In eyes with macular epiretinal membrane, the use of OCT may be helpful to determine the thickest part of the membrane, and the identifiable edge of the membrane. In Figure 1, the arrow indicates the edge of the membrane (Figure 1A, 1B), and shows the thickest part of the membrane (Figure 1C). We can start the peeling of the macular epiretinal membrane more easily if we have had this information by OCT preoperatively. Here we show that we performed vitrectomy with epiretinal membrane peeling on the basis of the OCT findings obtained preoperatively in Figure 2. We confirmed the area and thickness

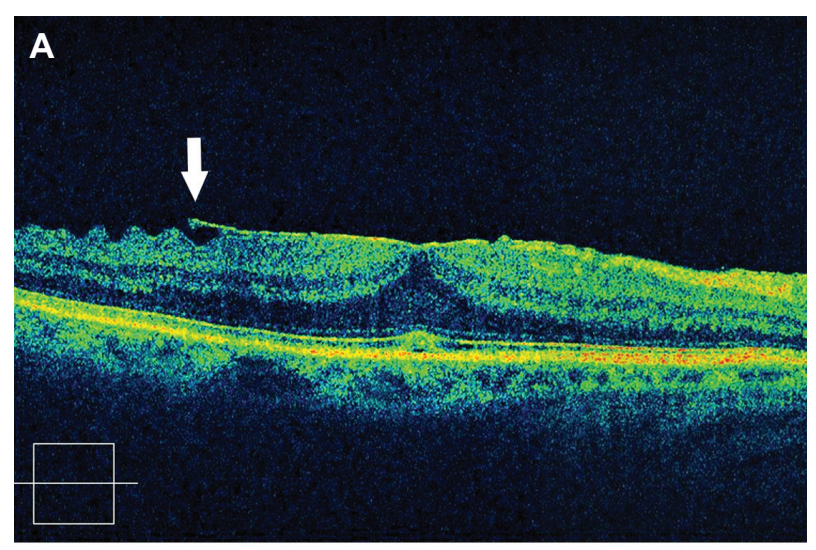

B

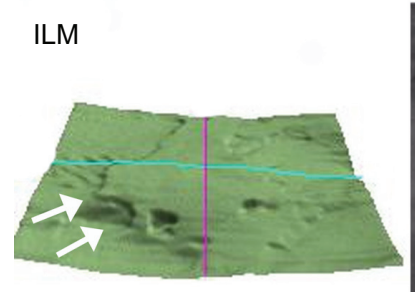

C

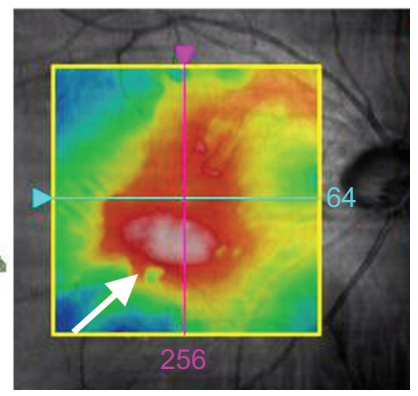

Figure I The right eye of a 7I-year-old patient with idiopathic epiretinal membrane. All OCT images are obtained by spectral-domain OCT (Cirrus ${ }^{\mathrm{TM}} \mathrm{HD}-\mathrm{OCT}$, Carl Zeiss Meditec, Jena, Germany). A) Horizontal image of optical coherence tomography (OCT) shows epiretinal membrane over the macula. . The arrow shows the identifiable edge of the membrane. B) Three dimensional retinal map images obtained by OCT. The arrows show the membrane that was elevated from the internal limiting membrane (ILM). C) Retinal map image obtained by OCT shows the range of epiretinal membrane. The arrow shows the thickest part of the membrane.

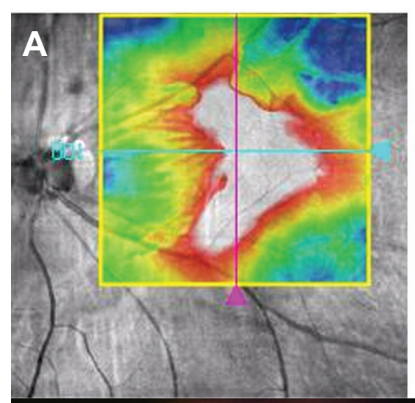

B ILM

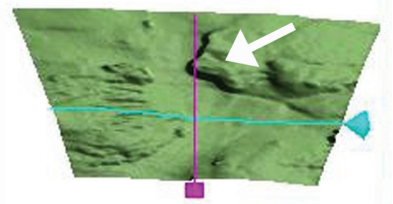

C

D

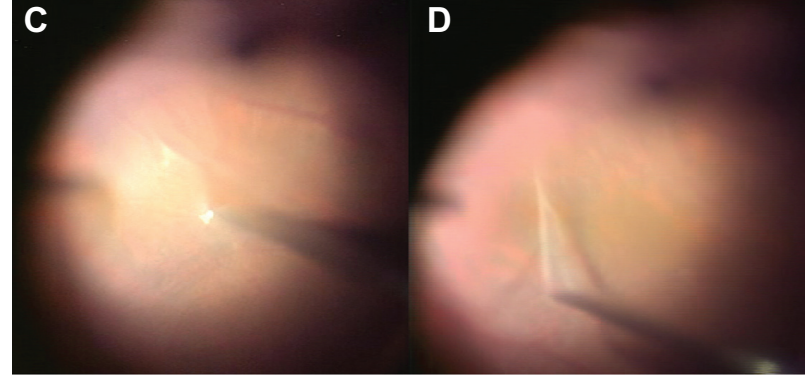

Figure 2 The right eye of a 75-year-old patient with idiopathic epiretinal membrane. A) Retinal map image obtained by optical coherence tomography (OCT) shows the range of epiretinal membrane. B) Three dimensional retinal map images obtained by OCT. The arrow shows the membrane that was elevated from the internal limiting membrane (ILM). C, D) Intraoperative photographs. C) 25-gauge micro-hooked needle was used to elevate the epiretinal membrane from the retinal surface. Because the membrane was elevated from the ILM (arrow) as shown by OCT (B) it was easy to pick up the edge of the membrane. D) One-piece membrane was removed by 25 -gauge micro-hooked needle.

of the epiretinal membrane (Figure 2A), found the edge of the membrane (Figure 2B), and started the peeling at that point (Figure 2C, 2D). We might be able to perform a surgery without any hesitation if we received these details of epiretinal membranes preoperatively.

There are no complications in this OCT-guided epiretinal membrane (ERM) peeling because OCT provides only additional information to assist the conventional procedure of ERM peeling. When the peeling point is located between the fovea and the optic disc, surgeons should take extra care when peeling or choose another peeling point. OCT-guided ERM peeling is useful in cases in which edges of the membrane are apart from the retinal surface, but all cases are applicable and beneficial because ERMs usually have a thickened portion. Edges of epiretinal membranes were not always detected by OCT, but a thickened area could be usually determined. To start peeling off the membrane at the thickened area might prevent a macula from being injured by a blade or needle, which is used for membrane peeling. Furthermore, findings obtained by OCT simplifies the procedure because we do not have to find the area where we should start membrane peeling during surgery. OCT-guided ERM peeling might be useful for dissecting ERM membranes. 


\section{Disclosure}

No conflicts of interest were declared in relation to this paper.

\section{References}

1. McDonald RG, Aaberg TM. Idiopathic epiretinal membranes. Semin Ophthalmol. 1986;1:189-195.

2. Kwok AK, Yeung YS, Lee VY, et al. ICG-assisted peeling of the retinal ILM. Ophthalmology. 2002;109:1040.
3. Feron EJ, Veckeneer M, Parys-Van Ginderdeuren R, et al. Trypan blue staining of epiretinal membranes in proliferative vitreoretinopathy. Arch Ophthalmol. 2002;120:141-144.

4. Fraser EA, Cheema RA, Roberts MA. Triamcinolone acetonide-assisted peeling of retinal internal limiting membrane for macular surgery. Retina. 2003;23:883-884.

5. Huang D, Swanson EA, Lin CP, et al. Optical coherence tomography. Science. 1991;254:1178-1181.
Clinical Ophthalmology

\section{Publish your work in this journal}

Clinical Ophthalmology is an international, peer-reviewed journal covering all subspecialties within ophthalmology. Key topics include: Optometry; Visual science; Pharmacology and drug therapy in eye diseases; Basic Sciences; Primary and Secondary eye care; Patient Safety and Quality of Care Improvements. This journal is indexed on

Submit your manuscript here: http://www.dovepress.com/clinical-ophthalmology-journal

\section{Dovepress}

PubMed Central and CAS, and is the official journal of The Society of Clinical Ophthalmology (SCO). The manuscript management system is completely online and includes a very quick and fair peer-review system, which is all easy to use. Visit http://www.dovepress.com/ testimonials.php to read real quotes from published authors. 